\section{Metatarsus adductus in two brothers with Aarskog syndrome}

In 1970, Aarskog ${ }^{1}$ described a new syndrome, the facialdigital-genital syndrome, involving seven family members. The syndrome consists of short stature, characteristic facies, 'saddle bag' scrotum, and brachydactyly with mild interdigital webbing. Other features have been less constant, encompassing the skeletal and connective tissue systems. To date, none of the Aarskog patients has had bony deformities requiring surgical correction. A patient with the Aarskog syndrome and severe metatarsus adductus necessitating surgical correction is presented.

A 6-year-old white male presented with severe metatarsus adductus which had been treated from the age of 2 weeks with manipulation and serial cast changes. The metatarsus adductus was relatively rigid and recurred rapidly out of casts. Outflare last shoes and Denis Browne splints were not tolerated. At the age of 5 years, recurrent metatarsus adductus was noted and surgery suggested, but deferred until one year later.

Physical examination revealed a short dysmorphic 6year-old white male with a height of $117 \mathrm{~cm}$ and weight of $22.3 \mathrm{~kg}$. He had hypertelorism and a short nose and anteverted nares (figure). Bilateral herniorrhaphy scars

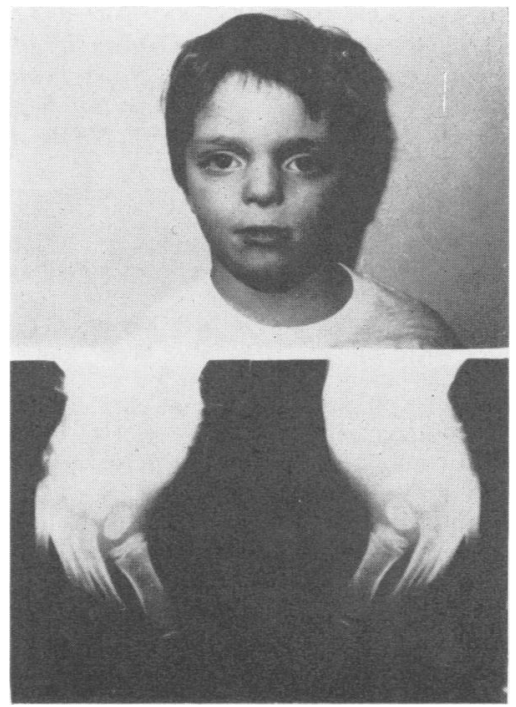

FIGURE The proband aged 6 years and radiograph of his feet.

The views of the author do not purport to reflect the positions of the Department of the Army or the Department of Defense.

Received for publication 11 May 1983.

Accepted for publication 13 June 1983 . and a small umbilical hernia were present. Scrotal skin folds were overriding the base of the penis. The hands showed brachydactyly with clinodactyly of the fifth fingers, an unusual position of the extended fingers, and mild interdigital webbing. A severe rigid metatarsus adductus, pes cavus, and normal valgus heels were present.

The patient's brother had the identifying features of the Aarskog syndrome and had a similar foot deformity surgically corrected at the age of 5 years. The mother, with partial features of the syndrome, a widow's peak, and mild hypertelorism, had a mild adductus. All other family members were reported not to have the syndrome.

Radiological studies showed the severe metatarsus adductus and cavus of the feet (figure). The patient underwent bilateral mobilisation of tarsometatarsal and intermetatarsal joints by capsulectomy and ligamentous release. He was immobilised in plaster for 3 months with satisfactory correction of the metatarsus adductus and cavus deformities.

The Aarskog syndrome is well recognised and affects solely the skeletal and connective tissue systems resulting in a characteristic set of anomalies. The skeletal anomalies seen in this syndrome have included vertebral deformities, cubitus valgus, and metatarsus adductus. ${ }^{2}$ Little emphasis has been placed on foot malformations but several Aarskog patients described have had foot deformities. They include small broad feet, flat feet with internal tibial torsion, metatarsus primus varus, and metatarsus adductus. $^{2} 3$

The foot deformities in the Aarskog syndrome are a manifestation of the underlying skeletal and ligamentous defects. Of the six Aarskog patients already reported with metatarsus adduc!us, only two have been treated with casts and none surgically repaired. ${ }^{2}{ }^{3}$ In this family all three members had metatarsus adductus with associated findings. Surgical correction was only undertaken after the deformity recurred in both males. Geneticists need to be aware of the potential need for orthopaedic surgery in this syndrome.

DANIEL L Hurst Department of Pediatrics, Fitzsimmons Army Medical Center, Aurora, Colorado 80045, USA.

\section{References}

1 Aarskog D. A familial syndrome of short stature associated with facial dysplasia and genital anomalies. $J$ Pediatr 1970;77:856-61.

2 Funderburk SJ, Crandell FF. The Aarskog syndrome in three brothers. Clin Genet 1974;6:119-24.

3 Berman P, Desjardins C, Fraser FC. Inheritance of the Aarskog syndrome. Birth Defects 1974;10, No 7:151-9.

Correspondence and requests for reprints to Dr D L Hurst, Department of Pediatrics, Fitzsimmons Army Medical Center, Aurora, Colorado 80045, USA. 